\title{
Descentralización política e impuestos en la Carta de 1991
}

Political decentralization and taxes in the 1991 Charter

Autor: Jorge Enrique Patiño Rojas

DOI: https://doi.org/10.19053/16923936.v19.n38.2021.13692

Para citar este artículo:

Patiño Rojas, J. E. (2021). Descentralización política e impuestos en la Carta de 1991. Derecho y Realidad, 19 (38), 77-93. 


\title{
DESCENTRALIZACIÓN POLÍTICA E IMPUESTOS EN LA CARTA DE 1991
}

\author{
Political decentralization and taxes in the 1991 Charter
}

\section{Jorge Enrique Patiño Rojas}

Doctor en historia por la Universidad Pedagógica y Tecnológica De Colombia - Uptc. Docente, investigador, escritor y conferencista. jorgeepr@yahoo.es

Recepción: Noviembre 30 de 2020

Aceptación: Abril 26 de 2021

\section{RESUMEN}

En cualquier forma de Estado, las entidades territoriales tienen la posibilidad de establecer los elementos de alguno o algunos impuestos (hecho generador, base gravable, sujetos activo y pasivo, y tarifa). Estos pueden ser previamente determinados por la ley, la cual sería la forma más genuina de descentralización política; sin embargo, en Colombia, por disposición constitucional de 1886 a la fecha, la competencia impositiva entre la Nación y las entidades territoriales ha sido decidida en favor de aquella. Soslayándose de esta manera dos posibilidades de descentralización política que a través de tributos establece la vigente Constitución. No obstante, la

primera con arraigo en 1886; la segunda con fuente en 1991, y por omisión política del Congreso y tácita anuencia de la Corte Constitucional, en cuanto finalmente no se ha expedido adecuadamente la respectiva ley orgánica de ordenamiento territorial que lo permita. Esta situación que propicia que la Nación continúe manteniendo su preeminencia, casi sesquicentenaria, en el tema político-impositivo.

\section{PALABRAS CLAVES}

Descentralización política; impuestos; competencia impositiva; tópica jurídica; regiones; entidades territoriales.

\footnotetext{
* Artículo de reflexión
} 


\section{ABSTRACT}

In any form of State, the territorial entities have the possibility of establishing the elements of one or more taxes (generating event, taxable base, active and passive subjects, and tariff). These can be previously determined by law, which would be the most genuine form of political decentralization; However, in Colombia, by constitutional provision of 1886 to date, the tax competition between the Nation and the territorial entities has been decided in favor of the former. Bypassing in this way two possibilities of political decentralization that the current Constitution establishes through taxes. However, the first with roots in 1886; the second with source in 1991, and by political omission of the Congress and tacit consent of the Constitutional Court, as soon as the respective organic law of territorial ordering that allows it has not been properly issued. This situation that encourages the Nation to continue to maintain its preeminence, almost 150 years old, in the political-tax issue.

\section{KEYWORDS}

Political decentralization; taxes; tax competition; legal topic; regions; territorial entities.

\section{INTRODUCCIÓN}

En este artículo examinamos dos posibilidades constitucionales. Se parte de la eventualidad que ofrece al nivel territorial (art. 338) en 1848 en la República de la Nueva Granada con la ley del 3 de junio, que dio libertad a provincias, cantones y distritos parroquiales en la aprobación de sus propios tributos. Por su parte, la citada norma constitucional de 1991, además del Congreso Nacional, igualmente pareciera dar libre juego a asambleas departamentales y a concejos municipales en la aprobación de cargas impositivas para departamentos y municipios, respectivamente. Sin embargo, los textos de los artículos 287-3, 300-4 y 3134, limitan esta competencia a lo dispuesto por la Constitución y la ley, generándose una aparente contradicción en el vigente cuerpo constitucional. Por lo mismo, en este punto, nuestro desarrollo es hermenéutico, basado en la tópica como lugar común, en nuestro caso, político-jurídico. La otra opción, embotada en lo político, pero jurídicamente más viable en favor del orden subnacional, la establece el art. 307, complementario del 306 constitucionales, pues permite la creación de las regiones como entidades territoriales; de donde, finalmente, puede surgir la posibilidad de legislación residual en materia tributaria.

Así las cosas, cualquier forma políticojurídica que posibilite legislar en tributos a las entidades territoriales sería un buen legitimador institucional complementario de la democracia participativa existente en Colombia y, lo más significativo, a través de la gobernanza -surgida de la concientización tributaria-, se fortalecería el sistema político, tan precario visto desde la trayectoria de nuestra organización estatal. Al respecto, Mora y Enríquez afirman,

"La inexistencia de conciencia tributaria, tanto a nivel individual como colectivo... se motiva por una desconfianza generalizada hacia el Estado y al papel que juega en el cumplimiento de sus objetivos centrales" (Mora y Enríquez, 2017, pp. 273-292). Teniéndose esta, con razón, como causa principal de la evasión y elusión tributaria, por lo que se hace necesario maximizar las contribuciones voluntarias (Macías, y Cortés, 2004, pp. 19-42). Situación que amerita análisis porque, según Mockus, "[p]osiblemente cada persona se dé el lujo de ser altruista o kantiano cotidiano en relación con algunas de las múltiples acciones colectivas que una sociedad ofrece, dando píe a reutilizar el lema de la tributación voluntaria en muchos campos" (Mockus, 2003, pp. 65-80). Por lo mismo, para Garay y Espitia dicen "resulta indispensable recabar en la necesidad impostergable de imponer todos los correctivos que sean idóneos y eficaces para combatir la evasión y la elusión tributarias, tan elevadas y onerosas económica y socialmente para el país". (2020, pp. 223-224) 
En Colombia, aunque la apertura democrática local, materializada en la elección popular de alcaldes (1988), posteriormente complementada con la elección de gobernadores (1992), se consideran dos acontecimientos democrático-participativos, tal vez los más importantes del siglo XX. No obstante, solo alcanzan para la concreción de autogobierno (self-government, en versión anglosajona), que en concepto lockiano apenas la materializan se da la legitimidad formal de las autoridades, pero que integrada con manejo parcial de poder permitiría cristalizar la autonomía política territorial mediante la facultad legislativa residual, complementaria y colaborativa en favor bien de departamentos (y municipios), o de las regiones. Estas fueron creadas como entidades territoriales mediante la respectiva ley orgánica de ordenamiento territorial. De contera se abrazaría la legitimidad material expuesta por Locke, en cuanto las autoridades territoriales elegidas tuvieran instrumentos propios y eficaces para cumplir los cometidos de felicidad que demanda cada comunidad, en nuestro caso, regional, seccional o local.

\section{COMPETENCIA IMPOSITIVA Y TÓPICA JURÍDICA}

En el texto de la Constitución de Colombia se halla una aparente contradicción entre dos mandatos suyos que aquí interpretamos en términos estrictamente político-jurídicos, valiéndonos de la tópica como lugar común que la retórica aristotélica habilitó como cliché fijo para la argumentación; pero que, seguidamente, fue retomada por la hermenéutica. Para Aristóteles, dichos lugares "se refieren en común... a muchas materias que difieren por la especie" (1994, pp. 190-191). Así las cosas, la idea entonces sentada por el propio presidente Gaviria, relativa a que la Constitución, estableció una "nueva democracia" y un "nuevo derecho", mantiene vigente una posible salida en favor de la democracia territorial. Y, según Vidal Perdomo, la Constitución tomó directamente el sitio de las normas (2016, pp. 143-155). Además, se evidencia que la administración pública está sometida más a la Constitución que a la ley (Montaña, 2014, p. 100).

Por un lado, el art. 338 pareciera dar libre juego tanto al Congreso de la República como a asambleas departamentales y concejos municipales en la aprobación de cargas impositivas, en cada caso, para la Nación, los departamentos y los municipios, como sus correspondientes sujetos activos. Los departamentos y municipios se amparan en la autonomía política prevista en la Constitución. Por el otro, lo dispuesto en los artículos 287-3, 300-4 y 313-4 limitan para las entidades territoriales dicha competencia a lo dispuesto en el marco constitucional y legal. En adelante se examinarán críticamente las disposiciones señaladas para precisar su contenido y determinar, por un lado, la competencia del Congreso en materia tributaria y, de contera, las competencias de las corporaciones territoriales de elección popular en el mismo tema.

Para su desarrollo, primero se precisa la literalidad de las normas materia de cotejo, de inicio el artículo 338, continuando con los artículos 287-3, 300-4 y 313-4. Seguidamente, mediante las posibilidades de interpretación jurídica que ofrece la tópica, como método argumentativo de conciliación de diferencias problémicas contenidas en un todo unitario, en nuestro caso, en el cuerpo constitucional, precisamos una salida político-jurídica. Es dable valerse de este instrumento retórico-filosófico porque, desde Aristóteles, quien le dio su nombre, integra el mundo de la filosofía; y como lo expresa Carnelutti, "[n]inguna rama de la ciencia vive sin respirar filosofía, pero esta necesidad es sentida en el Derecho más que en cualquiera otra [ciencia]... [Pues], a medida que se avanza por el camino de la jurisprudencia, el problema de lo metajurídico revela más y más su importancia decisiva" (Carnelutti, s.f., p. VIII).

\subsection{Normas bajo examen}

En el cuadro siguiente (1), para su análisis prima facie, en la columna de la izquierda, formando un todo (conjunto A), tenemos el art. 338 (que, paradójicamente, en lo básico, 
Tabla 1. Normas sobre impuestos Constitución Política de Colombia

\begin{tabular}{|c|c|}
\hline$A=[$ Art. 338] & $B=[$ Arts. 287-3, 300-4, 313-4] \\
\hline $\begin{array}{l}\text { "Entiempo de paz, solamente el Congreso, las asambleas departamentales } \\
\text { y los concejos distritales y municipales podrán imponer contribuciones } \\
\text { fiscales o parafiscales. La ley, las ordenanzas y los acuerdos deben } \\
\text { fijar, directamente, los sujetos activos y pasivos, los hechos y las bases } \\
\text { gravables, y las tarifas de los impuestos. } \\
\text { La ley, las ordenanzas y los acuerdos pueden permitir que las autoridades } \\
\text { fijen la tarifa de las tasas y contribuciones que cobren a los contribuyentes, } \\
\text { como recuperación de los costos de los servicios que les presten o } \\
\text { participación en los beneficios que les proporcionen; pero el sistema y } \\
\text { el método para definir tales costos y beneficios, y la forma de hacer su } \\
\text { reparto, deben ser fijados por la ley, las ordenanzas o los acuerdos. } \\
\text { Las leyes, ordenanzas o acuerdos que regulen contribuciones en las } \\
\text { que la base sea el resultado de hechos ocurridos durante un periodo } \\
\text { determinado, no pueden aplicarse sino a partir del periodo que comience } \\
\text { después de iniciar la vigencia de la respectiva ley, ordenanza o acuerdo" }\end{array}$ & $\begin{array}{l}\text { Art. 287. “Las entidades territoriales gozan de } \\
\text { autonomía para la gestión de sus intereses, y } \\
\text { dentro de los límites de la Constitución y la ley. } \\
\text { En tal virtud tendrán los siguientes derechos: } \\
\text { (...). 3. Administrar los recursos y establecer los } \\
\text { tributos necesarios para el cumplimiento de sus } \\
\text { funciones". } \\
\text { Art. 300. "Corresponde a las asambleas depar- } \\
\text { tamentales, por medio de ordenanzas: (...). } 4 . \\
\text { Decretar, de conformidad con la ley, los tribu- } \\
\text { tos y contribuciones necesarios para el cumpli- } \\
\text { miento de las funciones departamentales". } \\
\text { Art. 313. "Corresponde a los concejos: (...). } 4 . \\
\text { Votar de conformidad con la Constitución y la } \\
\text { ley los tributos y los gastos locales". }\end{array}$ \\
\hline
\end{tabular}

Fuente: Constitución Política. Elaboración del autor

su mandato viene del Acto Legislativo 3 de 1910, art. 60; 42 de la Carta de 1886); y en la columna de la derecha (conjunto B), están los artículos 287-3, 300-4 y 313-4.

En una primera apreciación, pareciera que el art. 338 hoy vigente, indistintamente, les diera libertad impositiva a todas las corporaciones públicas de elección popular de orden nacional, departamental y local (Congreso, asambleas y concejos), no así a las juntas administradoras locales (JAL). Pero esa libertad se ve limitada por la Constitución y la ley, vistos en conjunto los mandatos de los arts. 287-3, 300-4 y 313-4. Es una especie de laguna constitucional en esta materia, pues su solución no encuadra al interior de las normas en conflicto, por no ser claras, más bien sí incompatibles entre sí. Asimismo, en el entendido que por tratarse de una unidad político-jurídica la interpretación de la Constitución Política desborda los mandatos que para tal fin se establecieron en la ley (art. 5, Ley 57 de 1887). Así las cosas, para la solución de sus propias incompatibilidades debemos valernos de la tópica jurídica como técnica complementaria de interpretación constitucional. Pues, "la remisión de un argumento cualquiera a un 'lugar común' constituye un método por el que es posible sustituir las relaciones de inferencias espontáneas, que la razón realiza entre términos particulares, por las relaciones comunes y generales que son de aplicación a todos los casos" (Racionero, 1994, 190).

\subsection{La tópica como instrumento de interpretación jurídica}

Primero, entendida la tópica como como lugar común "de donde se extrae el material para la demostración" (Viehweg, 1964, p. 41), mediante la conciliación de situaciones antagónicas, como contradicciones entre leyes, en este caso de mandatos constitucionales. Se distingue como una técnica de pensamiento problemático, desarrollada por la retórica en su contextura espiritual, diferenciándose claramente del ánimo deductivo sistemático (Viehweg, 1964, p. 22). Para el caso bajo examen entendemos la tópica como una forma hermenéutica previa a la propia jurisprudencia.

En este sentido, la aparente o real contradicción entre los artículos constitucionales 338 (que pareciera otorgarle libre albedrío a asambleas y concejos para decretar tributos departamentales y municipales, respectivamente), y los artículos 287-3, 300-4 y 313-4 (que supeditan dicha facultad a la Constitución y a la ley), quedaría zanjada con el lugar común político-jurídico de la unidad nacional prevista en el art. 1 de la Constitución que, como República Unitaria 
advierte la existencia de un único lugar común de impulsión política, de leyes, en nuestro caso de contenido fiscal. Recayendo tal distinción y facultad en el Congreso de la República.

Sobre la ambivalencia de la competencia política de los departamentos se tiene el siguiente desarrollo constitucional: el art. 299 original de la Constitución previó que "[e]n cada departamento habrá una Corporación administrativa de elección popular que se denominará Asamblea Departamental...". El Acto Legislativo No. 1 de 1996, sin cambiar el anterior mandato, agregó que: "Dicha Corporación gozará de autonomía administrativa y presupuesto propio..... El Acto Legislativo 1 de 2003 (art. 16), estableció que: "En cada departamento habrá una Corporación de elección popular que ejercerá el control político sobre los actos de los Gobernadores, Secretarios de despacho, Gerentes y Directores de Institutos Descentralizados $y$, que se denominará Asamblea Departamental (...). Dicha Corporación gozará de autonomía administrativa y presupuesto propio...." Sin embargo, el texto del AL 1 de 2003 fue declarado inexequible por la Corte Constitucional, mediante sentencia C-668 de 2004. En el 2007, el AL 1 volvió a reformar el artículo 299, ratificando que "En cada departamento habrá una Corporación político-administrativa de elección popular que se denominará Asamblea Departamental..."; agregándole que "podrá ejercer control político sobre la administración departamental".

Por su parte, la Ley 489/98 (art. 39), estipuló que las asambleas departamentales y los concejos distritales y municipales son corporaciones administrativas de elección popular. Norma legal que, para las asambleas, contraría el mandato constitucional que indica que son corporaciones políticoadministrativas. En cambio, desde su origen constitucional, el Congreso de la República es una corporación política (legislativa), que le "corresponde hacer las leyes". Además, gozando de la prerrogativa de reserva legal en materia impositiva.
El aspecto político constitucional de las asambleas departamentales se pueden asumir como la capacidad para legislar, como su auténtica legitimidad; pues, de las variadas formas de poder del hombre sobre el hombre, en la tradición clásica, expresa Bobbio, el político es "el interés de quien gobierna y de quien es gobernado" (2005, p. 1216). Es el poder civil de Locke previsto sobre el consenso para que la sociedad pueda darse seguridad a fin de preservar la propiedad (1995, p. 173). Con esta atribución política a las dumas departamentales, ganada en décadas de madurez administrativa -sustitutiva de su antigua competencia política-, además, se honraría la teleología participativa del Estado colombiano desde el nivel intermedio, según Bakunin, ahora sí de gobierno, y no de mera administración.

A pesar del anterior marco políticojurídico de los departamentos, Liliana Estupiñán Achury (2012, p. 123) recoge la vieja idea que denota el marchitamiento de las asambleas departamentales, originalmente establecida en el informe de Finanzas Intergubernamentales Wiesner Bird (1981), y que insinúa su muerte institucional. Por análoga línea conceptual y jurídica, en particular valiéndose de la unidad nacional de la organización territorial de Colombia, a la fecha, la Corte Constitucional ha dejado sentado que no es posible interpretar que las entidades territoriales puedan legislar en materia impositiva o tributaria (ni en ninguna otra), solo cuando la ley lo autorice.

En materia de la autonomía financiera se estableció desde la sentencia C-517 de 1992 que los impuestos nacionales deben ser creados por la ley, los departamentales por ordenanzas y los municipales por medio de acuerdos, y que en todo caso '...los departamentos y municipios se encuentran sujetos al marco legal en la creación de sus tributos propios en virtud del principio de unidad nacional'. Así se indicó que en desarrollo de esta atribución constitucional los concejos municipales deben adoptar de conformidad con la Constitución y la ley los tributos y los gastos locales (art. 313.4 C. Pol.), dictar las normas orgánicas 
de presupuesto y expedir anualmente el presupuesto de rentas y gastos (art. 313.5 C. Pol.) (Corte Constitucional, Sentencia C-130, 28 de noviembre de 2018).

Por su parte, en 2016, el Consejo de Estado manifestó:

Esta Sala, en sentencia del 9 de julio de 2009, precisó que en vigencia de la Constitución Política de 1886, la facultad impositiva de los municipios era derivada en cuanto se supeditaba a las leyes expedidas por el Congreso, pero que con la norma superior promulgada en el año 1991, la ley, las ordenanzas y los acuerdos pueden determinar los elementos del tributo, de conformidad con los principios de descentralización y autonomía de las entidades territoriales concedidos a las asambleas departamentales y a los concejos municipales y distritales para establecer los diferentes aspectos de la obligación tributaria. Así mismo, señaló que el artículo 338 de la Constitución Política indica la competencia que tienen los entes territoriales para que, a través de sus órganos de representación popular, determinen los presupuestos objetivos de los gravámenes, de acuerdo con la ley, sin que tal facultad sea exclusiva del Congreso, pues de lo contrario se haría nugatoria la autorización que expresamente la Carta les ha conferido a los departamentos y municipios en tales aspectos. Agregó que la competencia en materia impositiva de los municipios, para el caso, no es ilimitada, pues no puede excederse al punto de establecer tributos ex novo, porque la facultad creadora está atribuida al Congreso, pero a partir del establecimiento legal del impuesto, los mencionados entes territoriales, de conformidad con las pautas dadas por la ley, pueden establecer los elementos de la obligación tributaria cuando aquella no los haya fijado directamente.

Así pues y en virtud de los principios de autonomía y descentralización territorial el criterio actual de la Sala en materia de facultad impositiva territorial reconoce la autonomía fiscal de los municipios y distritos para regular directamente los elementos de los tributos que la ley les haya autorizado (Consejo de Estado, Sentencia rad. 21035. C.P., 30 de marzo de 2016).

Así las cosas, actualmente, todo impuesto es creado por la ley con origen en el Congreso de la República. Ella fija el sujeto activo que siempre será un organismo público, bien la Nación o una entidad territorial y, en ocasiones, generalmente como beneficiaria parcial, una entidad administrativa (como las corporaciones autónomas y las áreas metropolitanas); nunca un ente particular, salvo el caso de la parafiscalidad, no de los impuestos. Así las cosas, por hermenéutica constitucional, en Colombia, las corporaciones territoriales de elección popular no pueden decretar impuestos aun cumpliendo el hecho de ser un cuerpo colegiado elegido popularmente, fidedigno depositario, fáctico y legal, de representación política. Naturaleza y composición sociopolítica que lo hace corresponder con el viejo principio de raigambre anglosajona: no taxation without representation. En consecuencia, mediante un proceso iniciado en 1886, hoy, vía jurisprudencial, los departamentos colombianos, aun siendo entidades territoriales, sólo gozan (¿o padecen?), el estatus de entidades administrativas.

Para el municipio, cuyo tratamiento es análogo al del departamento, Paula Robledo lo resuelve mediante el método común de interpretación sistémica, de la siguiente manera:

La autonomía tributaria de nuestros entes municipales está reconocida constitucionalmente y las normas que la regulan se encargan de dejar en claro que no es una autonomía absoluta; por el contrario, se encuentra limitada no solamente por la Constitución sino también por la ley (arts. 287, 313.4).

Pero, según lo dispuesto en el artículo 338 de la Constitución, podría entenderse que las Asambleas departamentales 
y los Concejos municipales tienen plena libertad para fijar tributos, puesto que en este precepto no se hace referencia explícita a que la potestad impositiva de los departamentos y municipios se encuentra limitada por la ley. No obstante, en todo caso, una interpretación sistemática, a partir de las demás disposiciones indicadas, lleva a dilucidar rápidamente cualquier posible confusión. (Robledo, 2010, p. 389)

En Colombia, con análogas razones a las anteriores, desde finales del decimonónico solo el Congreso conserva la autoridad tributaria, creadora de impuestos, dado su reconocimiento de único cuerpo colegiado con autoridad política de representación popular. Desde entonces, la competencia de las entidades territoriales en la materia quedó solo a partir del establecimiento legal del gravamen, de conformidad con las pautas dadas por el Parlamento, pudiendo disponer los elementos de la obligación tributaria cuando la ley no los haya fijado directamente. Con esta cicatera concepción institucional, defendida por el orden nacional, se cierra la posibilidad de hacer leyes a las corporaciones subnacionales de elección popular, para el caso bajo examen, en materia fiscal. De contera se entorpece la genuina autonomía política territorial, expresada en la función residual de legislar. Situación, concentradora de poder, que mal posiciona al Congreso en particular. En cambio, con su proceder, como en una especie de menudeo tributario, sí se arroga la función de hacer legisladores a asambleas y concejos, cuando, mediante su autorización legislativa, les permite fijar uno o varios elementos de los impuestos que ha creado a su favor. Olvidando que, desde Locke, antes que Montesquieu moderno creador de la tridivisión de poder, quedó claro lo inadecuado de esa práctica. Pues, expresa el médico inglés, que "[e]l poder de la legislatura, al derivarse de una cesión voluntaria del pueblo, y de una instrucción hecha por éste, no puede ser otro que el que positivamente le ha sido otorgado, a saber: el poder de hacer leyes, y no el poder de hacer legisladores. Por lo tanto, la legislatura está incapacitada para transferir a otros la autoridad de hacer leyes" (Locke, 1995, pp.148-149). Agregando que ella "no deberá ni podrá transferir a nadie el poder de hacer leyes, ni depositarlo en lugar diferente de aquel en el que el pueblo lo ha depositado" (Locke, 1995, pp. 149).

En consecuencia, en el vigente marco constitucional colombiano, para validar política y jurídicamente la posibilidad legislativa directa de las asambleas departamentales bastaría darle solo a la Constitución el estatus de soberana, sobre la base de su art. 4; y a la ley la dimensión de autonomía política, como lo entiende Aja, constitucionalista catalán, es legítimo "poder para aprobar leyes" (1999). Además, así se aprovecharía el mandato constitucional que posiciona a la asamblea como "corporación político-administrativa de elección popular"; por lo que estaría jurídicamente habilitada para decretar impuestos. En lo políticosocial, sus leyes, amén de cercanas al ciudadano, serían forjadoras de la anhelada gobernanza y constructoras de comunidad, verdadera expresión de dominio político; y, además de honrar la participación ciudadana, se moderarían los niveles de violencia territorial.

Por otra parte, el Congreso tiene la genérica facultad de "revestir, hasta por seis meses, al Presidente de la República", para que mediante decretos con fuerza de ley legisle extraordinariamente. Empero, entre otras materias, tales facultades no podrán ser conferidas para decretar impuestos (art. 150-10), configurándose en pleno en Colombia la reserva legal en la materia impositiva. Frente al tema, nuestro máximo Tribunal constitucional ha expresado:

Para esta Corte, la reserva legal en materia tributaria y la correlativa exigencia de legitimidad democrática para las normas de índole fiscal, es uno de los pilares del modelo de estado constitucional, e impone un procedimiento democrático representativo como condición para la validez de los tributos -no tributación sin representación-, para evitar $l \neg 70$ abusos en un asunto que afecta directamente al ciudadano y que debe garantizar al mismo tiempo 
la sostenibilidad del Estado para el cumplimiento de sus funciones. (Corte Constitucional, Sentencia C-30, 30 de enero de 2019)

Imponiéndose en este punto precisar la diferencia con la legalidad, entendida como "la cualidad de aquello que es conforme a la ley" (Vedel, 1980, p. 219); pues, según Rivero, "conviene a la legalidad la imagen de una pirámide: desde la cima hasta la base, las reglas, según el nivel en que se sitúan, deben respetar las reglas superiores, y se imponen a la de los niveles subordinados" (Rivero, 1984, p. 84).

Entonces, en observancia de la reserva legal, a diferencia de la Constitución de 1886, la de 1991, prohibió la fijación de impuestos por vía extraordinaria (art. 150-10), quedando solo como competencia exclusiva del Congreso de la República y, a usanza de lo enseñado por Montesquieu, solo a iniciativa del ejecutivo (1993. p. 121). Así Colombia se puso a tono, entre otros, con países como Francia (1958) y España (1978), que en sus constituciones mantienen disposiciones similares (arts. 34 y 133, respectivamente), consolidándose de esta manera la formal legitimidad como el principio impositivo de reserva legal, derivado de un tiempo histórico braudeliano de larga duración.

Finalmente, además del mandato constitucional que dispone que "[e]n cada departamento habrá una Corporación político-administrativa de elección popular que se denominará Asamblea Departamental" (art. 299), un cotejo sobre el instituto de la reserva legal y la autonomía (tributaria) departamental, reciente, de la Corte Constitucional, se resume en el siguiente cuadro (2).

Tabla 2. Reserva legal vs autonomía departamental en la Corte Constitucional (2018-2019)

\begin{tabular}{|l|l|}
\hline \multicolumn{1}{|c|}{ Reserva legal } & \multicolumn{1}{|c|}{ Autonomía del departamento } \\
\hline "Para esta Corte, la reserva legal en materia tributaria y la & "En materia de la autonomía financiera se estableció \\
correlativa exigencia de legitimidad democrática para las & desde la sentencia C-517 de 1992 que los impuestos \\
normas de índole fiscal, es uno de los pilares del modelo de & nacionales deben ser creados por la ley, los departa- \\
estado constitucional, e impone un procedimiento democrático & mentales por ordenanzas y los municipales por medio \\
representativo como condición para la validez de los tributos - & de acuerdos, y que en todo caso '... los departamentos \\
no tributación sin representación-, para evitar l--os abusos en & y municipios se encuentran sujetos al marco legal en \\
un asunto que afecta directamente al ciudadano y que debe & la creación de sus tributos propios en virtud del prin- \\
garantizar al mismo tiempo la sostenibilidad del Estado para el & cipio de unidad nacional” (CC. Sent. C-130, M.P. José \\
cumplimiento de sus funciones" (CC. Sent. C-30, M.P. Cristina & Fernando Reyes Cuartas. 28 nov. 2018). \\
Pardo. 30 enero 2019). & \\
\hline
\end{tabular}

Fuente: Cotejo reserva legal vs autonomía departamental, de Jorge Patiño Rojas.

En el cuadro (2) notamos que las características de la reserva legal descritas por el Tribunal de cierre constitucional, aunque referidas al Congreso Nacional, son (formal y materialmente) aplicables a la asamblea departamental, pudiendo así ella legislar en materia tributaria. La diferencia estriba en que la corporación seccional aún se tiene, mental y jurídicamente, como entidad administrativa (art. 39, L. 489798). Por otra parte, paradójicamente, es claro que en la Constitución la autonomía departamental tributaria solo está sujeta al marco legal.
Finalmente, insistimos que están dadas las condiciones para que en Colombia las asambleas departamentales puedan legislar, en nuestro caso en fiscalidad, basta darle a la ley solo el estatus de autonomía política y no de soberana; reservando este privilegio solo para la Constitución Política, valiéndonos de su art. $4^{\circ}$ que la posiciona como ley de leyes.

\section{LAS REGIONES COMO ENTIDADES TERRITORIALES}

En Colombia, desde la Constitución de 1991, quedó institucionalizada la posibilidad 
político-jurídica de creación de las regiones como entidades territoriales, situación que, de contera, análogo a como sucede en España (art. 150, Constitución de 1978), les generaría competencia legislativa $\mathrm{y}$, entre éstas, tributarias como sujetos activos de los impuestos que disponga la ley. No obstante, cabe aclarar que, según Aja, en aquel país las comunidades autonómicas presentan diferencias estructurales entre ellas (1999, p. 155). Agregando, cómo, por ejemplo, el régimen económico y fiscal especial de Canarias tradicionalmente ha tenido un tratamiento especial por su carácter insular y su lejanía de la península, por lo que la propia Constitución le proporciona cierta garantía como región ultra-periférica (1999, p. 178). Para Colombia proponemos que, de manera homogénea en lo jurídico, a través de la región baje al nivel subnacional la figura de la autonomía política (legislativa), entre otras materias, en tributación. En ese escenario, se tendría un nuevo avance democrático político, que superaría la formalidad de la participación ciudadana en la elección de las autoridades territoriales; primero de autoridades municipales, del acalde en particular a partir del Acto Legislativo 1 de 1986, con concreción inicial a partir del 13 de marzo de 1988. En 1991, segundo, además de la aprobación de la elección de gobernadores de los departamentos, los artículos 306 y 307 constitucionales dejaron sentadas las bases para que, en el futuro inmediato, mediante ley orgánica, se diera vida político-jurídica a las regiones como entidades territoriales y de esta manera, junto con la Nación, pudieran ejercer la función legislativa, configurándose así un avance real en la descentralización política, este sí como verdadero reparto de poder en el territorio, en nuestro estudio, en materia fiscal. Entendiendo que lo fiscal, particularmente su concepto tributario, por su trascendencia social forma parte integral de lo político, tal como se halla consignado tanto en la larga tradición parlamentaria inglesa como en el apogeo de los municipios castellanos de los siglos XII y XIII.

No obstante, los ejemplos regionalistas europeos del siglo XX (España, Italia y Francia), nuestro derecho, fortalecido por el ensayo de la Confederación Granadina (1858), y retomando el pensamiento constitucional desde nuestra propia cabeza (Guadarrama, 2001, pp. 385-392), debe poner en marcha la autonomía regional prevista en la Carta Política. Para su examen, primero se hace referencia al contenido de los artículos constitucionales 306 y 307 y, seguidamente, la consecuente legitimación formal y material de la institucionalidad, que surgiría a partir del nuevo orden territorial. Continuando con la omisión legislativa absoluta del Congreso en la materia, aun la expedición de las leyes 1454 y 1962; y la respectiva inhibición de la Corte Constitucional al abordar el estudio de la primera de estadas dos leyes. Finalmente, atendiendo la perspectiva histórica, proponemos el modelo de Estado-región, la forma más plausible de legitimidad política para Colombia.

\subsection{Normas constitucionales}

El contenido de los artículos 306 y 307, es el siguiente:

Tabla 3. De entidad administrativa a territorial. Constitución Política de Colombia

\begin{tabular}{|c|c|}
\hline Art. 306 & Art. 307 \\
\hline $\begin{array}{l}\text { "Dos o más departamentos podrán } \\
\text { constituirse en regiones administrativas } \\
\text { y de planificación, con personería } \\
\text { jurídica, autonomía y patrimonio } \\
\text { propio. Su objeto principal será el } \\
\text { desarrollo económico y social de la } \\
\text { respectiva región". }\end{array}$ & $\begin{array}{l}\text { "La respectiva ley orgánica, previo concepto de la comisión de ordenamiento } \\
\text { territorial, establecerá las condiciones para solicitar la conversión de la región } \\
\text { en entidad territorial. La decisión tomada por el Congreso se someterá en cada } \\
\text { caso a referendo de los ciudadanos en los departamentos interesados. } \\
\text { La misma ley establecerá las atribuciones, los órganos de administración, y los } \\
\text { recursos de las regiones y su participación en el manejo de los ingresos prove- } \\
\text { nientes del fondo nacional de regalías. Igualmente definirá los principios para la } \\
\text { adopción del estatuto especial de cada región". }\end{array}$ \\
\hline
\end{tabular}

Fuente: Constitución Política. Elaboración del autor. 
En Colombia, es claro que, con una adecuada expedición de la Ley Orgánica de Ordenamiento Territorial (LOOT), a aprobar por mayoría absoluta de los miembros de una y otra cámara (art. 151 C.P.), y para lo cual no es legal otorgar facultades extraordinarias al Presidente de la República (art. 150-10 C.P.), se podrían establecer las regiones como entidades territoriales $y$, de contera, estas tendrían la facultad de expedir normas legislativas cristalizadoras de efectiva autonomía política territorial.
Para nuestro análisis, en el siguiente cuadro (No. 4), se grafican ejemplos de los modelos universales de reparto del poder en el territorio: i) la Federación Norteamericana, ii) el Estado autonómico español, y iii) el Estado colombiano como República Unitaria en sus dos versiones, la del deber ser, si se expidiere correctamente la ley orgánica de ordenamiento territorial que de vida política a las regiones territoriales que ella instituya; y la del ser, esto es, lo que hoy se tiene.

\section{Tabla 4.}

\begin{tabular}{|l|l|l|l|}
\hline \multicolumn{2}{|l|}{ Representación gráfica del poder en el territorio } \\
\hline $\begin{array}{l}\text { Sistema Federal } \\
\text { (EE.UU.) }\end{array}$ & $\begin{array}{l}\text { Estado Autonómico } \\
\text { (España) }\end{array}$ \\
\hline (Colombia)
\end{tabular}

Fuente: Jorge Patiño Rojas

Como se puede apreciar en el cuadro 4 , en primer lugar, cada entidad federativa (en EEUU), utilizando la original figura del sistema federal, tiene competencias residuales tanto en función constituyente (y constitucional), como en legislativa, jurisdiccional y administrativa. Por su parte, el ensayo autonómico de España -en este ejemplo-, otorga a sus regiones competencias residuales en función legislativa, y eso que aun por Constitución tiene como fundamento la "indisoluble unidad de la Nación española" (art. 2, Constitución de 1978). Por su parte, Colombia, como República Unitaria centralizada en lo político, sin desarrollo adecuado del art. 307 constitucional, la fórmula de la competencia residual de sus unidades territoriales, aun posibilitándose por el referido mandato constitucional, sigue siendo únicamente de tipo administrativo; y en lo político solo una quimera.

\subsection{Legitimidad institucional}

Se decía que el autogobierno solo alcanza para la ejecución de la descentralización política participativa; por lo mismo el desarrollo legal adecuado del art. 307 de la Carta Política, permitiría cristalizar la autonomía política territorial mediante la facultad legislativa residual-cooperativa. Si bien la elección popular de mandatarios subnacionales es y ha sido el acontecimiento democrático más importante del siglo XX en Colombia, en cuanto simultáneamente involucra dos elementos fundamentales: la participación popular y la legitimidad política formal de las autoridades; no obstante, hasta aquí el proceso de descentralización política está cercenado, porque el auténtico poder político, materializado en su ejercicio, se sigue manejando íntegramente, como ha sido desde 1886, a partir de instancias 
del gobierno central, en la capital de la República. Entonces, incluso después de la elección de autoridades locales y seccionales, ni siquiera de manera parcial, política y jurídicamente, ellas han podido ejercer un verdadero dominio (al menos fragmentado), que implique un genuino poder político, que se pueda traducir en la capacidad legislativa, residual-colaborativa, en nuestro caso en materia impositiva. Coincidiendo con nuestro planteamiento, Lorena Suárez expresó que en Colombia

[1]as normas tributarias están urgidas de legitimidad formal y sustancial. A la primera responde el procedimiento democrático que se debe observar para la aprobación de los tributos y contribuciones fiscales y parafiscales. La segunda sólo se satisface en la medida en que el deber tributario se enmarque en los conceptos de equidad, justicia y seguridad. (Suárez, 2003. pp. 323-364)

Por lo mismo, como verdadero complemento del aspecto democráticoparticipativo, también para el orden territorial, es necesaria la debida aprobación de la figura político-jurídica establecida en el art. 307 de la Constitución Política, mediante la ley orgánica de ordenamiento territorial. Con un correcto desarrollo legal de este mandato constitucional, sin ambages, surgiría la genuina autonomía política que supera la puramente participativa; pues, es claro que

Autonomía significa, etimológicamente, poder para aprobar leyes, y en sentido amplio suele equipararse a autogobierno, porque no solo son importantes las leyes sino también el conjunto de elementos que intervienen en las políticas públicas, como la dimensión de la administración y los recursos financieros. El autogobierno de las CCA es notable: sus instituciones solo responden ante el propio electorado, sin ninguna dependencia jerárquica respecto al gobierno central; poseen poder legislativo, reglamentario y administrativo sobre ámbitos tan importantes para los ciudadanos como el urbanismo, la educación, el medio ambiente, etc. (Aja, 1999, p. 14)

Por lo mismo, en cuanto a la instauración democrática territorial-legislativa, el profesor Clemente Forero, evaluando la descentralización y la participación ciudadana, en particular en fiscalidad, concluye que en Colombia "[u]na propuesta de participación para la eficiencia requiere considerar aspectos más allá de lo político [participativo]. [Argumentando que] es necesario que los ciudadanos se involucren en las decisiones del gasto e ingreso público" (Forero, 1997, p. 204), para lo cual, entre otras medidas, sugiere su intervención directa en la planeación y el diseño presupuestal, situación que de manera directa implica legislación en materia impositiva por cuenta de las regiones, en el evento que se llegaren a crear en debida forma político-jurídica.

\subsection{Reglamentación inicial de los artículos 306 y 307 constitucionales}

Previo a cumplir los 20 años de expedida la Carta de 1991, mediante la Ley 1454/11, el Congreso reglamentó las anteriores normas constitucionales. No obstante, históricamente, además de omisiva, la actuación institucional del Estado ha sido evasiva del tema, pues, primero, el Congreso demoró en aprobar la ley orgánica que desarrollará la Constitución y le diera vida política a las regiones territoriales $\mathrm{y}$, segundo, aunque después de "más de 19" proyectos presentados fue aprobada la Ley 1454/11, la misma evadió enteramente el tema central, del que debía ocuparse: establecer "las condiciones para solicitar la conversión de la región [administrativa] en entidad territorial", con atribución de legislar mediante una especie de competencias residuales, en moderna versión mutual, con respecto a las competencias políticolegislativas de la Nación, no de las político-constitucionales.

Por su parte, al estudiar la demanda de inconstitucionalidad contra la Ley 1454, por la omisión legislativa, la Corte Constitucional se declaró inhibida para fallar de fondo 
argumentando que dicha omisión fue absoluta, lo que, expresa, según su historial jurisprudencial, le impide abordar el mérito del asunto. La síntesis de este proceso Congreso - Corte Constitucional, es la siguiente:

\subsubsection{Ley 1454 del 28 de junio de 2011}

Por la cual se dictan normas orgánicas sobre ordenamiento territorial y se modifican otras disposiciones. Esta Ley, retomando el mandato constitucional estipulado para la Región Territorial, decretó que: "De conformidad con el artículo 307 de la Constitución Política la Región Administrativa y de Planificación podrá transformarse en Región Entidad Territorial, de acuerdo con las condiciones que fije la ley que para el efecto expida el Congreso de la República" (art. 36). A continuación se coteja con la norma constitucional.

Tabla 5. La región como entidad territorial: de la norma constitucional a la legal

\begin{tabular}{|c|c|}
\hline Art. 307 Constitucional & Art. 36, Ley 1454 (LOOT) \\
\hline $\begin{array}{l}\text { "La respectiva ley orgánica, previo concepto de la } \\
\text { comisión de..., establecerá las condiciones para solicitar } \\
\text { la conversión de la región en entidad territorial. } \\
\text { La decisión tomada por el Congreso se someterá } \\
\text { en cada caso a referendo de los ciudadanos en los } \\
\text { departamentos interesados". (subrayas fuera de texto). }\end{array}$ & $\begin{array}{l}\text { "De la Región Territorial. De conformidad con el artículo } 307 \text { de } \\
\text { la Constitución Política la Región Administrativa y de Planificación } \\
\text { podrá transformarse en Región Entidad Territorial, de acuerdo } \\
\text { con las condiciones que fije la ley que para el efecto expida el } \\
\underline{\text { Congreso de la República". (subrayas fuera de texto). }}\end{array}$ \\
\hline
\end{tabular}

Fuente: Art. 307 constitucional y art. 36 de la LOOT. Resumen del autor.

Lo consignado en el art. 36 de la Ley 1454, reprodujo el contenido básico, de plazo indefinido, del art. 307 constitucional, pues, igual que la norma superior, transfirió en la ley, en una nueva ley (orgánica), las condiciones (que fijará el Congreso), para el paso de la región como entidad administrativa a la región como entidad territorial. Lo correcto, según el mandato constitucional, hubiera sido que la propia Ley orgánica 1454, fijara dichas condiciones, pero no lo hizo. Continuando, como desde 1991, con la inconstitucionalidad por omisión, entendida como "la falta de desarrollo por parte del Poder Legislativo, durante un tiempo excesivamente largo, de aquellas normas constitucionales de obligatorio y concreto desarrollo, de forma tal que se impide su eficaz aplicación" (Díaz, 2016, pp. 129-153). En la Sentencia C-489/12, que resolvió la demanda de inconstitucionalidad de la Ley 1554 (LOOT), el Alto tribunal constitucional "zanja" el problema jurídico retomando vieja jurisprudencia de su seno, pues dice que al respecto en el 2000 había expresado que: “... se ha dicho que lo relativo al ordenamiento territorial, que debe tramitarse como ley orgánica, bien puede desarrollarse en diversos cuerpos normativos, siempre que éstos cumplan con el limitante de haber sido tramitados y aprobados como leyes orgánicas" (Corte Constitucional. Sentencia C-795, 29 de noviembre de 2000).

\subsubsection{Sentencia C-489/12}

(27 de junio), mediante la cual se resuelve la demanda de inconstitucionalidad interpuesta contra la Ley 1454/11 (LOOT). En primer lugar, citando nutrida jurisprudencia constitucional, alude a que siendo una omisión absoluta la que trae la Ley enjuiciada, no puede haber control de constitucionalidad por ausencia de un parámetro normativo. Al respecto expresó: “...esta Corte ha establecido desde las sentencias C-073 y C-543 de 1996 que cuando la demanda se estructura sobre la base de una omisión legislativa absoluta, es decir, cuando existe ausencia total de legislación, no se cuenta con un parámetro normativo para realizar el control y por ende la demanda no procede en este caso porque la Corte carece de competencia para realizarlo" (Corte Constitucional. Sentencia 
C-489, 27 de junio de 2012) Por lo mismo, agrega:

Teniendo en cuenta lo anterior se verifica que en la Ley 1454 de 2011, se omite de manera absoluta un desarrollo directo de las regiones como entidades territoriales del artículo 307 de la C.P. (...), ya que solo se establecen normas que remiten a una posterior regulación de dichos deberes constitucionales. Por tal motivo, se advierte que en el presente caso, lo que se presenta en el caso concreto es una ausencia total de legislación produciéndose de esta manera una omisión legislativa absoluta no sujeta de control por parte de esta Corte. (Corte Constitucional. Sentencia C-489, 27 de junio de 2012)

Con este panorama político-jurídico nugatorio que, paradójicamente, aún con ley, incluye la omisión legislativa absoluta del legislador en la fijación de las condiciones para la conversión de la región administrativa en entidad territorial, y el correspondiente fallo inhibitorio de la Corte Constitucional, se seguía aplazando uno de los anhelos del Constituyente de 1991, la posibilidad de la autonomía política regional y la consecuente capacidad legislativa residual que implicaría el fortalecimiento territorial en materia fiscal, de ingresos y gastos públicos. Con origen en lo político, la solución es puramente normativa, que la ley orgánica establezca a cabalidad las condiciones para poder solicitar la conversión de la región administrativa en territorial. Por ahora, preocupa ese criterio remolón del Legislador -cobijado por la posición jurisprudencial de la Corte-, que legisla, pero no legisla. Así Colombia rememora la historia novelada de El Gatopardo, en la segunda mitad decimonónica en Sicilia, donde queda sentado el statu quo total (incluido el legislativo), impuesto por el régimen de aquella Isla, pues Tancredi, sobrino del príncipe, tuvo como máxima que "[s]i queremos que todo siga como está, es preciso que todo cambie". (Lampedusa, 1983, p. 29)

\subsection{Ley 1962}

Nuevamente el 28 de junio de 2019, al cumplir los 8 años de estar rigiendo la Ley 1454, el Congreso expidió la Ley 1962, Por la cual se dictan normas orgánicas para el fortalecimiento de la región administrativa de planificación, se establecen las condiciones para su conversión en región entidad territorial y se dictan otras disposiciones, en desarrollo de los artículos 306 y 307 de la C.P. En síntesis, dentro de las atribuciones de las posibles regiones territoriales (art. 9), esta nueva ley no les estableció la facultad de decretar tributos. Por lo mismo, en el tema impositivo, objeto del presente análisis, seguimos en déficit. Pues, en versión de la norma constitucional, "[l]a misma ley establecerá las atribuciones, los órganos de administración, y los recursos de las regiones y su participación en el manejo de los ingresos provenientes del fondo nacional de regalías". Sin embargo, esta ley guardó silencio sobre la posibilidad de decretar impuestos para funcionamiento, solo estipuló que: "Los recursos de inversión de la Región Entidad Territorial (RET) provendrán de los aportes de las entidades territoriales que concurran en su conformación, los recursos provenientes del crédito publico y la cofinanciación del presupuesto general de la Nación y de otras fuentes de financiación territorial, las donaciones en su favor y los demás que establezca la constitución y la ley, en concordancia con sus funciones"; evadiéndose por completo, nuevamente, la fiscalidad regional, en particular su aspecto tributario. Al respecto, ante eventual impugnación, solo quedaría pendiente el pronunciamiento del máximo Tribunal constitucional sobre la Ley 1962, en particular si la omisión legislativa dejó de ser absoluta ameritando en tal evento control de constitucionalidad de fondo.

\subsection{Conclusiones. Propuesta regional para Colombia}

De acuerdo con Fals Borda, en Colombia "[e]l pluralismo cultural, humano y ambiental sigue predominando como fórmula vital entre nosotros... La diversidad 
reconocible y reconocida en la unidad nacional queda consagrada con mecanismos adecuados en la ley en ciernes" (1996, p. viii). En este sentido, la Ley 1962 registró el Hecho Regional, como "un fenómeno territorial que por su naturaleza poblacional y espacial trasciende las escalas de gobierno local y departamental en materia de competencias, inversión, planeación y ejecución de proyectos, requiriendo una atención conjunta para que las acciones que se desarrollen sean eficientes y efectivas, y conduzcan al desarrollo integral de la región" (art. 3). Sin embargo, en específico en materia fiscal, de la Región, la ley en mención solo se refirió a la administración de recursos y no de tributos (art. 10-b). En cambio, sus análogas ibéricas, expresa el art. 133-2 de la Constitución española, "podrán establecer y exigir tributos de acuerdo con la Constitución y las leyes". Esto a pesar de que la misma Carta ibérica estipula la potestad tributaria originaria exclusivamente al Estado, mediante ley (art. 133-1); empero, aclara que tal facultad puede ser delegada en los niveles subcentrales de Gobierno.

En consecuencia, atendiendo el componente histórico, en Colombia se hace menester establecer la competencia tributaria en favor de las entidades territoriales; pues, aunque "[n]o vamos a reconstruir la sociedad solo con las pautas del pasado, ni vamos a retroceder la historia..., no es dable dejar de lado ese rico acumulado social e histórico que hemos examinado y lo mucho que ha quedado por fuera para pensar que podemos resolver los problemas del momento "ex novo" haciendo tabla rasa de la historia y de la cultura acumulada. iQue despilfarro si estos estudios no impelieran hacia adelante y nos dieran mejores herramientas para hacer frente a nuestros retos!" (Fals Borda, 1996, p. 67).

No obstante, en nuestro sentir, si llegare a entrar en funcionamiento en debida forma la región territorial conformada por departamentos, sería adecuado que, para evitar la congestión de tantos niveles territoriales, y su posible anarquía, a criterio del Legislador, se abolieran otros niveles espaciales menos relevantes para propiciar la armonización integral del territorio nacional. Evento que podría desacomodar privilegios, algunos bicentenarios, aún más venidos de la colonia; siendo oportuno recordar que el patrimonio político del gobernante se gasta gobernando.

Desde el punto de vista epistemológico, bueno sería, con la práctica, creando la Región territorial con autonomía políticatributaria, ensayar en Colombia el modelo intermedio de organización territorial del Estado, pues como lo expresan Bobbio y Bovero: "Buenas teorías no son solamente las que siguen la realidad en su marcha caótica, buscando descifrar la suma de los efectos indeseables y leer escrupulosamente los movimientos de la historia; sino son también, y quizás sobre todo, las que anticipan la realidad, buscando proporcionar criterios de evaluación y orientar los acontecimientos para darles dignidad como proyectos conscientes y racionales" (1984, p. 16); agregando con razón, "en ello radica la fuerza de la filosofía política".

Finalmente, del examen de las leyes de ordenamiento territorial en Colombia se puede concluir que el Congreso ha soslayado por omisión legislativa su deber político, y la Corte Constitucional por inacción jurisprudencial pretextando que en cuanto dicha omisión es absoluta, ella omite pronunciarse, por ahora sobre el texto de la Ley 1454. Como obligación nuestra insistimos en que política y jurídicamente en Colombia están dadas las condiciones para que algún nivel territorial pueda legislar residualmente y para la armonía de tal finalidad con la unidad nacional basta darle a la ley el grado de autonomía política y solo a la Constitución la condición de soberana.

Concluimos que hasta hoy, en Colombia, la autonomía política territorial solo tiene el alcance de participación popular en la escogencia de sus autoridades, y no el ejercicio residual de poder, por ausencia de competencia legislativa de los niveles subnacionales de administración, no de gobierno. Por lo mismo, siendo los impuestos la más ortodoxa y extendida expresión de poder político del Estado liberal, para 
legitimarlos, sería necesario otorgarles alguna capacidad legislativa (residual) a las entidades territoriales existentes (departamentos y municipios), o crear adecuadamente las regiones como entidades territoriales para que automáticamente tengan dicha facultad. Se acataría así el grito de la historia que, en una democracia real, enseña la directa relación impuestos y representación, pues a más genuina representación más consentimiento de los impuestos, hasta que estos, idealmente, como eran los tributos, regresen a ser voluntarios.

\section{REFERENCIAS BIBLIOGRÁFICAS}

» Aja, Eliseo. (1999). El Estado Autonómico. Federalismo y hechos diferenciales. Madrid: Alianza editorial.

» Aristóteles. (1994). Retórica. Madrid: Gredos, pp. 190-191.

» Bobbio, Norberto, et al. (2005). Diccionario de Política. 10 xico: Siglo XXI. p. 1216.

» Bobbio, Norberto y Bovero, Michelangelo. (1984). Origen y fundamentos del poder político. México: Grijalbo, p. 16.

»Carnelutti, Francesco. (s.f). Metodología del Derecho. 3 ed. Bogotá: Lib. del profesional.

» Díaz Gamboa, Luis Bernardo. (2016). La inconstitucionalidad por omisión. Necesidad de reconocimiento de la figura en Colombia como factor garantista de los Derechos Humanos. En: IUSTA, No. 28. Tunja: Universidad Santo Tomas de Aquino, pp. 129-153.

» Estupiñán Achury, Liliana. (2012). Desequilibrios territoriales: Estudio sobre la Descentralización y el Ordenamiento Territorial colombiano. Una Mirada desde el Nivel Intermedio de Gobierno. Bogotá: Universidad del Rosario, Doctrina y Ley, p.123.

» Fals Borda, Orlando. (1996). Región e Historia. Elementos sobre ordenamiento y equilibrio regional en Colombia. Bogotá: TM Editores-IEPRI UN, p. viii.

» Forero, Clemente, et al. (1997). Descentralización y participación ciudadana. Bogotá: TM Editores, Universidad Nacional, p. 204.

» Garay Salamanca, Luis Jorge y Espitia Zamora, Jorge Enrique. (2020). Desigualdad y reforma estructural tributaria en Colombia: Hacia una economía política de inclusión social. Bogotá: Ediciones desde abajo, pp. 223-224.

» Guadarrama, Pablo. (2001). Humanismo en el pensamiento Latinoamericano. Tunja: Universidad Pedagógica y Tecnológica de Colombia, pp. 385-392.

» Lampedusa, Giuseppe Tomassi (de). (1983). El Gatopardo. Bogotá: Oveja Negra, p. 29.

» Locke, John. (1995). Segundo tratado sobre el gobierno civil. Barcelona: Altaya, p. 173.

» Macías, Hugo y Cortés, Jaider. (2004). Disminuir la tarifa general de IVA en Colombia aumentaría el recaudo tributario. En: Semestre económico, Vol. 7, Núm. 13. Medellín: Universidad de Medellín, pp. 19-42.

» Mockus, Antanas. (2003). Una revisión de logros y retos de Bogotá desde conceptos de Jon Elster. En: Reflexiones sobre la Investigación en Ciencias Sociales y 
Estudios Políticos. Bogotá: Universidad Nacional, pp. 65-80.

» Montaña Plata, Alberto y otro. (2014). La constitucionalización del derecho administrativo. En: XV Jornadas internacionales de derecho administrativo. Bogotá: Universidad Externado, p. 100.

» Mora, María y Enríquez, Jairo. (2017). Cumplimiento voluntario de las obligaciones tributarias. En: Unimar, Vol. 35, Núm.1. Pasto: Universidad Mariana, pp. 273-292.

» Montesquieu. Trad. Blázquez, Mercedes y Vega, Pedro de. (1993). Del espíritu de las leyes. Barcelona: Altaya, p. 121.

» Racionero. (1994). En: Aristóteles. Retórica. Madrid: Gredos, p. 190.

» Rivero, Jean. (1984). Derecho Administrativo. Caracas: Universidad Central, p. 84.

» Robledo Silva, Paula. (2010). La autonomía municipal en Colombia. Bogotá: Universidad Externado, p. 389.

» Suárez Fierro, Lorena. (2003). El poder tributario como emblema de la democracia. El principio de legalidad como límite del poder tributario desarrollado jurisprudencialmente. En: Lecturas de derecho fiscal. Bogotá: Universidad Externado, pp. 323-364.

» Vedel, Georges. (1980). Derecho administrativo. Madrid: Biblioteca Jurídica Aguilar, p. 219.

» Vidal Perdomo, Jaime. (2016). Algunas consideraciones sobre el control de constitucionalidad en Colombia. En: Derecho y Realidad, Vol.4 No. 8. Tunja: Universidad Pedagógica y Tecnológica de Colombia, pp. 143-155.

» Viehweg, Theodor. (1964). Tópica y jurisprudencia. Madrid: Taurus, p. 41.

\section{Leyes}

» Asamblea Constituyente. (1991). Constitución Política de la República de Colombia. 2 ed. Bogotá: Gaceta Constitucional No. 116.

» Congreso de la República. (2011, 28 de junio). Ley 1454 por la cual se dictan normas orgánicas sobre ordenamiento territorial y se modifican otras disposiciones. Bogotá: Diario Oficial. Nro. 48115.

» Congreso de la República. (2019, 28 de junio) Ley 1962 por la cual se dictan normas orgánicas para el fortalecimiento de la región administrativa de planificación, se establecen las condiciones para su conversión en Región Entidad Territorial y se dictan otras disposiciones, en desarrollo de los artículos 306 y 307 de la C. P. Bogotá: Diario Oficial. 2019. nro. 50998.

\section{Jurisprudencia}

» Consejo de Estado. (30 de marzo de 2016). Sección 4ä. Sentencia rad. 21035. C.P. Carmen Teresa Ortiz de Rodríguez.

$»$ Corte Constitucional. (28 de noviembre de 2018). Sentencia C-130, M.P. José Fernando Reyes Cuartas.

» Corte Constitucional. (29 de noviembre de 2000). Sentencia C-795, M.P. Eduardo Cifuentes Muñoz.

$»$ Corte Constitucional. (27 de junio de 2012). Sentencia C-489, M.P. Adriana María Guillén Arango. 